\title{
B Corps' Social Media Communications during the COVID-19 Pandemic: Through the Lens of the Triple Bottom Line
}

\author{
Manveer Mann ${ }^{1}$, Sang-Eun Byun ${ }^{2, *}$ and Whitney Ginder ${ }^{3}$ \\ 1 Department of Marketing, Feliciano School of Business, Montclair State University, Montclair, NJ 07043, USA; \\ mannm@montclair.edu \\ 2 Department of Retailing, College of Hospitality, Retail and Sport Management, University of South Carolina, \\ Columbia, SC 29208, USA \\ 3 Department of Management, Marketing, \& Logistics, College of Business, Georgia College \& State University, \\ Milledgeville, GA 31061, USA; whitney.ginder@gcsu.edu \\ * Correspondence: sbyun@mailbox.sc.edu
}

Citation: Mann, M.; Byun, S.-E.; Ginder, W. B Corps' Social Media Communications during the COVID-19 Pandemic: Through the Lens of the Triple Bottom Line. Sustainability 2021, 13, 9634. https:// doi.org/10.3390/su13179634

Academic Editor: Yoonjae Nam

Received: 3 August 2021

Accepted: 25 August 2021

Published: 27 August 2021

Publisher's Note: MDPI stays neutral with regard to jurisdictional claims in published maps and institutional affiliations.

Copyright: (c) 2021 by the authors. Licensee MDPI, Basel, Switzerland. This article is an open access article distributed under the terms and conditions of the Creative Commons Attribution (CC BY) license (https:/ / creativecommons.org/licenses/by/ $4.0 /)$.

\begin{abstract}
The COVID-19 pandemic and rising demand for transparency has heightened the importance of sustainability communications on social media to generate deeper stakeholder engagement. Although B Corporations (B Corps), businesses committed to the triple bottom line (TBL), could serve as a catalyst for sustainable development, little is known about how they communicate on social media during a crisis. Therefore, we examined social media communications of B Corps to (1) identify salient topics and themes, (2) analyze how these themes align with the TBL, and (3) evaluate social media performance against industry benchmarks. We focused on the apparel, footwear, and accessories (AFA) sectors in the U.S. and chose Twitter, a platform known for crisis communication. Using a qualitative method, we found four topics and 21 underlying themes. Topics related to social/environmental issues and COVID-19 were most dominant, followed by product/brand promotions. Further classification of specific themes and cases from a TBL perspective demonstrated that, overall, B Corps in the AFA sectors leveraged various approaches to promote balance between each TBL dimension. Lastly, although collectively B Corps exceeded some of the Twitter industry benchmarks, at an individual level, most brands had room for improvement to build a stronger community and promote synergy among the three pillars of the TBL.
\end{abstract}

Keywords: triple bottom line; B Corporations; COVID-19; social media; communication

\section{Introduction \\ "Serving a global community of people using businesses as a force for good." -B Lab}

A growing emphasis on stakeholder values of social and environmental responsibility and the triple bottom line (TBL) thinking led to the emergence of B Corporations (hereafter B Corps) in 2006 [1]. The TBL posits that sustainability encompasses three pillars including social, environmental, and economic dimensions, and businesses should incorporate all three dimensions [2]. B Corps are social enterprises that are committed to the TBL and certified by B Lab, a non-profit organization that assesses corporations' overall impact of their decisions on their workers, customers, community, and the environment. As of July 2021, 4049 corporations in 77 countries are certified [3]. The assessed impact comprises a range of factors, including but not limited to, supply chains, raw materials, charitable contributions, and employee benefits, which are reinforced by transparency and accountability measures [3]. Because B Corp certification is reassessed every three years, substantial effort and continuous commitment are required to become and maintain the status of a certified B Corp. Therefore, certification signals sustainability as a "core value" or "way of doing business" and can help companies develop an authentic, purpose-driven corporate identity and differentiate from corporations engaging in "greenwashing" and/or "woke washing" [3,4]. 
Moreover, the COVID-19 global pandemic has accelerated consumer demand for authentic, sustainable, and inclusive business practices. A recent IBM study that surveyed 14,000 adults from nine countries indicated that environmental issues are more important to them as a result of COVID-19, and specifically, they highly valued safeguarding freshwater supplies, reducing pollution, protecting ecosystems and species, and addressing climate change [5]. The IBM study further noted that consumer demand has accelerated sustainable investments grounded in environmental, social, and governance factors in portfolio selection, which led to an increase in investment by 96\% from 2019 to 2020 .

This shift is likely to boost stakeholders' interest in B Corps as their brand purpose and values are embedded in responsible and ethical practices. As a result, communicating sustainability to the public is becoming more critical for transparent and legitimate communications [6,7]. Social media is increasingly serving as one of the primary channels to communicate with stakeholders about corporate values and initiatives and build a reputation [8]. For example, a study found that when companies promote corporate social responsibility (CSR) initiatives on social media they can shift consumers' sentiment about the corporation from neutral to positive [9]. This effect can be particularly pronounced for B Corps, given their authenticity and commitment for the greater good. Additionally, because the majority of B Corps are small to medium-sized businesses [3], social media is integral for communication as it offers low barriers to entry to reach a large audience around the globe [10]. Furthermore, the interactive nature of social media allows businesses to measure engagement with corporate communication and build relationships with different types of stakeholders [11,12].

Although B Corps could serve as important "catalysts" for social and environmental changes [1], little is known about how B Corps communicate and perform on social media. More importantly, there is no known study that examined how or whether messages that sustainable businesses, such as B Corps, communicate on social media support the TBL. Furthermore, the COVID-19 pandemic has fueled concerns about fundamental problems rooted in society and the environment. Given that B Corps prioritize creating value for nonshareholding stakeholders, including employees, the community, and the environment [1], understanding how they navigate a crisis and communicate on social media is particularly relevant and meaningful to further the success of the B Corp model and to promote sustainability on a global scale. Furthermore, the TBL provides a comprehensive framework to implement and communicate sustainability to stakeholders. This framework can be used to evaluate the range of individual B Corp's social media communications to identify the strengths and the areas of improvement which could help them improve communication effectiveness via higher visibility and engagement. Therefore, the purpose of this study is to examine how B Corps communicate on social media in the face of a global crisis. Specifically, using a qualitative research method, we explore the following research questions:

(1) What are the major topics and underlying themes in B Corps' communications on social media during the COVID-19 pandemic? What are the most frequently communicated messages? How are sustainability messages communicated on social media?

(2) How are B Corps' social media communications aligned with the TBL framework? Are there any specific dimensions (social, environmental, or economic) of sustainability that are more prominently featured on social media than others?

(3) How do B Corps perform on social media in comparison to the industry benchmarks? Are there any patterns in social media performance metrics by the brand's follower size or overall B Impact Score?

Among various social media platforms available, this study analyzes B Corps' communications on their corporate Twitter accounts. We chose Twitter, a text-based platform, as it has been noted as the most suitable for analyzing messages, and corporations often use Twitter to promote their sustainability-related information [11,12]. Twitter has also been identified as an effective platform for crisis communication; however, much research has focused on brands' use of Twitter to deal with internal corporate crises (e.g., product recalls, scandals). Thus, there is need to explore companies' communication strategies 
in times of collective crisis, like the COVID-19 pandemic. In addition, we focus on the apparel, footwear, and accessories (AFA) sectors in the U.S. The AFA sectors are replete with ethical transgressions across the supply chain, ranging from labor to environmental abuses. Moreover, the apparel/fashion sector accounts for $10 \%$ of carbon emissions; it is the second-largest consumer of water, with textile dyeing specifically being the second-largest polluter of water [13]. To make matters worse, the demand for clothing has accelerated in recent decades. Consumers bought $60 \%$ more clothes in 2014 than in 2000, and $57 \%$ of the discarded clothing ends up in landfills. Given the magnitude of the environmental consequences of the AFA sectors, B Corps can catalyze positive change and a sustainable future. Therefore, by targeting B Corps in the AFA sectors, we can evaluate their focused messages in social media communications and identify opportunities to improve shareholder engagement and advance sustainability development.

\section{Literature Review}

\subsection{The Triple Bottom Line Framework}

As per the UN World Commission on Environment and Development, sustainability can be defined as "meeting the needs of the present without compromising the ability of future generations to meet their own needs" [14] (p. 16). Corporations committed to sustainability leverage the TBL framework to examine the impact of their businesses. The TBL, also known as Triple-P (People, Planet, and Profit), posits that businesses should be responsible for their social and environmental impact in addition to economic performance [15]. The social, or "people", dimension focuses on building social capital through positive relationships with various stakeholders. It includes improving lives of people through fair treatment or welfare policies, contributing to the communities, providing educational opportunities to their stakeholders, and more [15]. The environmental, or "Planet", dimension focuses on securing or expanding natural capital by improving the health of the planet by doing no harm or minimizing the impact on the environment [15]. It includes preserving natural resources, protecting the land, air, and water, reducing waste, producing sustainable materials or products, and using renewable energy [16]. The economic, or "Profit", dimension pertains to the overall economic equity for the society the company serves, not just internal profits of the company [15]. It includes improving the benefits of their offerings, promoting sales and brand image, reducing production costs, and contributing to the economic growth of the communities, such as creating jobs [16-18]. Therefore, sustainable corporations leverage the TBL to drive positive change by evaluating a comprehensive set of social, environmental, and economic impacts on a broad range of stakeholders, including employees, community members, customers, activists, and regulatory institutions [19].

However, balancing the triple bottom lines can be challenging, as economic, social, and environmental dimensions can be conflicting at times. Walker et al. [20] note that businesses should embrace the tensions between the three dimensions and develop synergies between them. Walker et al. [20] found that high performance in one dimension is correlated with high performance in other dimensions, regardless of external shocks/economic conditions (e.g., great recession). Furthermore, they found a significant increase in the market valuation of businesses (i.e., economic capital) when they used creative and synergistic solutions to address all three aspects of the TBL.

While the TBL encourages businesses to incorporate the three pillars into their agenda, not all businesses fully leverage it. Particularly, when the TBL is used as an accounting/reporting tool, non-financial impact can be difficult to report, and companies may pick what they want to report rather than presenting the complete picture [21]. In such cases, companies can use the TBL as a smokescreen to signal sustainable business practices but may not actually consider the TBL to inform business decision-making or to drive positive change. In a recent commentary, Elkington [2], who coined a concept of the TBL in 1994, stresses that corporations should account for the full cost of doing business, and B Corps hold promise in their commitment to the TBL as they focus on a "best for the world" outlook. 


\subsection{The B Corp Certification}

B Corp certification entails several steps, including meeting the basic standards of the performance assessment (B Impact Assessment), fulfilling all legal requirements, and undergoing transparency and verification procedures. For approved companies, annual certification fees vary by geographic region and annual sales volume. For example, companies with annual sales lower than USD 150,000 pay USD 1000 per year, while companies making between USD 750 million and USD 999.9 million pay USD 50,000 annually [3]. The certification is coordinated by the B Lab which is overseen by multiple governing and advisory bodies [3]. Specifically, the B Impact Assessment required for B Corp certification breaks the social and environmental impacts of a business into five impact areas, including governance, workers, community, environment, and customers. First, governance impact examines whether the company has a social/environmental mission and how it engages stakeholders to achieve this mission. It evaluates the overall mission, ethics, accountability, and transparency within the company. Second, workers impact area focuses on the overall work environment. It measures compensation, benefits, training, work culture, worker health, safety, and more. Third, community impact addresses a company's supplier relations, diversity, and engagement with the local community as well as charitable giving and addressing social issues. Fourth, environmental impact focuses on environmental performance of a company by assessing its facilities, materials, emissions, resource and energy use, as well as the environmental impact of its supply chain. It also evaluates whether the product of a company addresses environmental issues, such as reducing waste and wildlife conservation. Finally, impact on customers focuses on the public benefit of the products a company offers. It assesses if products provide a solution for a social or environmental issue, such as public health, preservation of the environment, and so on [3]. To be certified as a B Corp, a company is required to achieve a minimum of 80 points out of 200 available on the B Impact Assessment [3]. The B Corp impact assessment categories and underlying attributes demonstrate the complexity, commitment, and resources needed to fully integrate the three pillars of sustainability in the business. Therefore, to incorporate sustainability as a core value, companies must consider it from the perspective of the three dimensions of the TBL and the various stakeholders impacted by the TBL.

\subsection{Sustainability Communications on Social Media}

Communication of a firm's sustainable practices influences consumers' brand choices and purchase decisions by enhancing brand visibility, reputation, and trust [22,23]. Companies have used various means to communicate their sustainability, including websites, CSR reports, and social media [23-25]. In particular, social media is an important platform to examine sustainability communication because there is representation from a global audience, and it provides an avenue for stakeholders to co-create communication and express their opinions, experiences, and values, which can help build a stronger community and develop more effective communication strategies to promote sustainability [24,26].

However, companies have a fragmented understanding of how to strategically communicate their sustainability-related information or effectively persuade their various stakeholders [23]. Previous research focusing on communication strategies has used the public relations model of one-way communication and two-way communication as a framework. For example, Etter [27] examined three CSR communication strategies on Twitter: broadcasting, reacting, and engaging. Etter [27] found that despite the ease of facilitating two-way communication on social media, most companies used Twitter for broadcasting to disseminate information to stakeholders (one-way communication), followed by the reacting strategy (e.g., replies), and only a few companies used the engaging strategy to proactively reach out to their stakeholders and engage them in a dialogue. Consistently, within the context of Facebook, Cho et al. [22] found that corporations engaged in the informing strategy more often than they used the interaction strategy. As such, despite the effectiveness of interactive communication on positive stakeholder outcomes, these studies suggest that corporations do not fully leverage the interactive nature of social 
media [10,22,27]. Etter [27] attributed this to corporations' reluctance to communicate and engage with consumers regarding CSR-related issues. This reluctance is also reflected in the findings of Cho et al. [22] and Artemova [11], wherein they found that non-CSR messages (e.g., product/service/corporate information) generated more engagements than CSR messages. These results may indicate that, in general, consumers are naturally attracted to promotional content that is relevant, interesting, and rewarding. However, simply sharing promotional content or delivering sustainability content may not be effective enough to generate deeper levels of consumer engagement or participation.

Furthermore, several studies pointed out fundamental problems of sustainability communications, such as consumers' lacking awareness and knowledge of firms' sustainability practices and consumers' underlying attitudes toward external CSR communications. For example, in a study of German travelers, Tölkes [28] found that 43\% of them were not aware of companies' sustainability practices. In a study of the five most sustainable brands in Finland, Artemova [11] found that only $16 \%$ of the content these brands communicated on social media contained sustainability messages. The lack of companies' commitment or consumer engagement can be also partially attributed to consumers' skepticism toward CSR or sustainability claims. Studies report that companies often face scrutiny as consumers tend to have high skepticism toward external sustainability claims, questioning the company's internal or moral motivation [29]. Therefore, many companies are hesitant to communicate their practices [11] or intentionally avoid external CSR claims, thus taking a position of greenhushing. Greenhushing can cause consumers to question the company's motives and triggers perceived hypocrisy due to the absence of clear communication to the public, which negatively affects consumer behavior, such as purchase intentions [30]. Growing concerns about consumers' negative attitudes or criticism toward CSR or sustainability communication highlight the importance of transparent and authentic communication of corporate responsibility and sustainable practices [11,22].

\section{Materials and Methods}

\subsection{Brand Selection}

We identified certified B Corps listed on the B Corp's Directory (www.bcorporation.net) (accessed on 1 June 2020). As of June 2020, there were 46 certified corporations in the AFA sectors in the U.S. Using Keyhole, a social listening and analytics software program, we downloaded posts generated on the corporate Twitter accounts from 11 March 2020 to 11 September 2020. This timeframe was selected to analyze B Corps' messages for a six-month period beginning from the World Health Organization's official announcement of the COVID-19 pandemic. Of the 46 brands, 12 brands were excluded because they did not have a Twitter account $(n=6)$, their Twitter accounts had been inactive $(n=3)$, or the brands did not create any posts on Twitter during this period $(n=3)$. In total, 34 brands were included for the thematic analysis.

\subsection{Data Coding and Analysis}

Using the qualitative content analysis method, we identified patterns in B Corps' communications. We included original tweets only, excluding brands' replies, quoted tweets, or retweets. During the six-month timeframe, these brands created 2392 tweets in total. To balance the brand representation in our data, we included up to the 10 most engaging tweets from each brand, which yielded a total of 315 tweets. These top posts were selected based on engagements (likes and retweets) to examine the key content that resonated most with each brand's target audience.

We used a grounded theory approach in analyzing themes and patterns in the Twitter posts. First, one of the investigators created an initial coding scheme by using an open coding method and coded tweets into first-level concepts. This was based on tweets from the first five brands in the sample list and entailed reading the data several times to create distinctive labels that reflected the underlying concepts. Then using a constant comparison approach, we identified and refined the emerging themes, wherein two other investigators 
coded the same posts independently using the initial coding scheme. From this first-order coding, we then conducted axial coding to identify codes related to the first-level concepts. The coding scheme was expanded and revised as we analyzed new posts and found new categories. Based on the discussions, revisions were made to make clear distinctions among the coding categories. Three investigators coded all posts independently and discussed any differences in coding until a consensus was reached. When a post covered more than one category in our coding scheme, up to three different codes were assigned to a single post. For example, Allbirds' tweet "To our US healthcare community-we want to thank you for being on the front lines and helping to keep our communities healthy. We hope a pair of Tuke Matcha Wool Runners on us might be a small token of our appreciation" was given two codes, one corresponding to recognition of healthcare workers and a second code regarding COVID-19 related donations. On average, each post was assigned 1.84 codes.

\section{Results}

\subsection{Sample Profiles}

Among the 34 B Corps, the overall B impact scores ranged from 80 points to 151 points, with 80 being the minimum score required for the B Corp certification $(M=95.79, S D=19.41)$ (see Figure 1). When comparing specific impact area scores (i.e., governance, workers, community, environment, and customers), the community impact $(M=35.05, S D=18.74)$ yielded the highest scores for 19 brands (55.89\%), as compared with the environment impact $(M=22.36, S D=11.85)$ for eight brands $(23.53 \%)$, and the workers impact $(M=20.08$, $S D=5.97)$ for two brands $(5.88 \%)$. The governance impact showed the lowest score $(M=14.44, S D=3.10)$, and no brand achieved the highest score in the governance category. Moreover, for most of these brands, the consumer impact was not assessed; therefore, the scores were not available. Dhana Inc. had the highest overall and community scores (overall $=151.9$, community $=110.4$, environment $=26.6$, workers $=\mathrm{N} / \mathrm{A}$ ), closely followed by Patagonia (overall $=151.4$, community $=63.8$, environment $=43.5$, workers $=20.8$ ) . ChicoBag, on the other hand, had the highest environment score (overall $=114.6$, community $=24.5$, environment $=52.2$, workers $=19.6$ ), and AMS Fulfillment had the highest workers score (overall $=85.2$, community $=15.0$, environment $=14.2$, workers $=40.7$ ). TOMS had the highest governance score $($ overall $=121.5$, governance $=18.8$, community $=48.1$, environment $=22.4$, workers $=27.4)$.

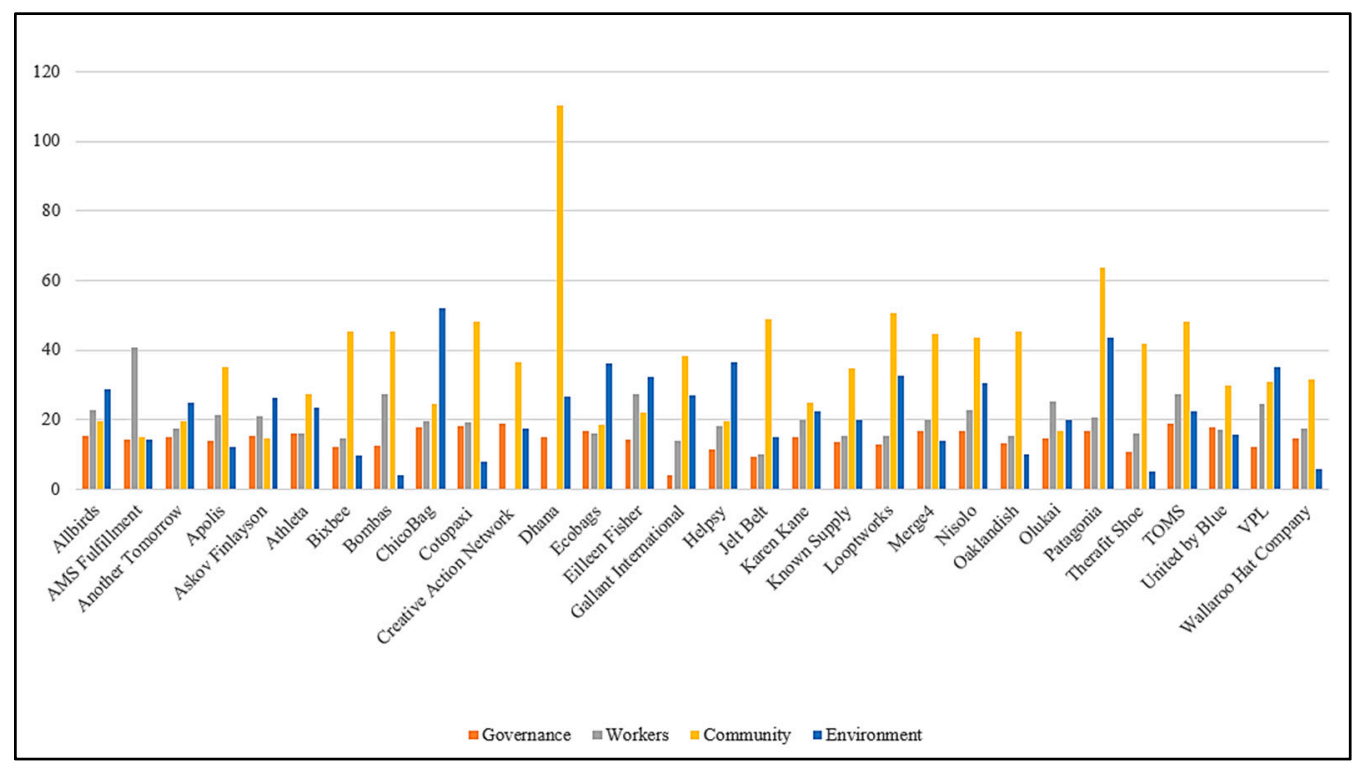

Figure 1. Overall B Impact Scores and Impact Area Scores by Company. 


\subsection{Thematic Analysis}

To answer Research Question 1, we examined thematic patterns in B Corps' communications on Twitter and found four major topics: social and environmental, COVID-19, product/brand promotion, and general topics (see Table 1). Among these topics, social and environmental was the most frequently mentioned topic $(36.24 \%, f=212)$, followed by COVID-19 $(34.70 \%, f=203)$, product/ brand promotion $(24.44 \%, f=143)$, and general topics $(4.62 \%, f=27)$. Below we provide detailed accounts of the various themes underlying each of the four topics and highlight representative posts for each theme. Topics and themes are discussed in order of frequency.

Table 1. Thematic Analysis-Frequency of Codes for Each Topic.

\begin{tabular}{|c|c|c|}
\hline Topic & Theme & Frequency \\
\hline \multirow{9}{*}{$\begin{array}{l}\text { Social \& Environmental } \\
\qquad(f=212)\end{array}$} & Sustainable materials/products/practices & 61 \\
\hline & Education and stakeholder engagement in sustainability & 51 \\
\hline & Miscellaneous causes & 19 \\
\hline & Racial issues & 18 \\
\hline & Environmental issues & 16 \\
\hline & Sustainability activism & 13 \\
\hline & Cause-related donation/fundraising & 13 \\
\hline & B Corp promotion & 11 \\
\hline & Media engagement and/or collaboration to promote sustainability & 10 \\
\hline \multirow{7}{*}{$\begin{array}{l}\text { COVID-19 } \\
(f=203)\end{array}$} & COVID-19 related donations/fundraising & 52 \\
\hline & Community engagement & 35 \\
\hline & Worker appreciation & 28 \\
\hline & Public health/safety advocacy & 28 \\
\hline & Product/promotion realignment & 27 \\
\hline & COVID-19 related collaboration and partner/influencer engagement & 17 \\
\hline & Store operation/production/distribution realignment & 16 \\
\hline \multirow{4}{*}{$\begin{array}{l}\text { Product/Brand Promotion } \\
\qquad(f=143)\end{array}$} & Collaboration and partner/influencer/media engagement & 56 \\
\hline & General product/brand promotion & 53 \\
\hline & Sales promotions & 29 \\
\hline & Other & 5 \\
\hline $\begin{array}{l}\text { General Topics } \\
\qquad(f=27)\end{array}$ & Generally relatable/motivational content (unrelated to the above three topics) & 27 \\
\hline
\end{tabular}

\subsubsection{Topic 1. Social and Environmental}

Nine underlying themes corresponded to the social and environmental messages. Under this topic, promoting sustainable products/practices and educating/encouraging stakeholders to participate in sustainability were the two most frequently mentioned themes. Various causes including racial and environmental issues were commonly communicated. There were also noticeable messages regarding activism, cause-related donations/fundraising, B Corp promotion, and media engagement/collaboration for a cause.

Theme 1. Sustainable Materials, Products, and Practices. Content featuring sustainable products and practices was the most salient theme under the social and environmental topic. There were 61 tweets. This theme includes messages promoting the use of sustainable materials, such as organic cotton, upcycled, repurposed, or re-engineered materials, or products made through sustainable or transparent practices. We found that the majority of these messages were informational, communicating about how their products are sustainably or ethically made or how they support or engage in fair trade or transparent supply chain practices. For example, Nisolo Shoes highlighted their initiative to go carbon neutral "In celebration of the 50th anniversary of \#EarthDay, we're thrilled to announce that Nisolo is going carbon neutral! Today, we're committing to offsetting the full scope 
of our environmental impact through the pursuit of Climate Neutral Certification". In another tweet, Gallant International Inc. promoted fair trade and ethical sourcing practices: "Fair Trade is more than a label. We are the farmers, the workers, the artisans, the fisherman. We are a global movement. Our mission? Make the right choice an obvious one..."

Theme 2. Education and Stakeholder Engagement in Sustainability. In total, 51 tweets shared educational content and/or engaged stakeholders in social/environmental sustainability. These posts presented news, opinions, and other informational resources to educate various stakeholders about sustainability. Some of them featured or promoted interviews, webinars, forums, or livestreaming. While most messages focused on educating stakeholders and raising awareness about the issue being discussed, some aimed at meaningful engagement by encouraging stakeholder participation or action in sustainable practices. The most frequently mentioned educational content was environmental issues. For example, Helpsy increased awareness regarding a clothing reuse and recycling initiative via the tweet, "Want to learn more about the future of clothing reuse and recycling from the experts? Check out Karine Vann's interview with Helpsy Co-Founder Dan Green at @WasteDive." Similarly, ChicoBag encouraged stakeholders to get involved in eco-friendly campaigns through the following tweet: "Sick of seeing beaches and rivers full of plastic and trash? Angry about the pollution and neglect our earth suffers daily?...Then it's time to \#effsingleuse. The 5th initiative of our Pledge to the Planet commitment is our \#EffSingleUse campaign..."

Theme 3. Miscellaneous Causes. The third most salient theme corresponding to environmental and social issues highlighted a range of different causes in 19 tweets including voting (related to the presidential election), small business support, gender equality, LGBTQ, hunger/poverty, refugees, health, and made in the USA. Among these causes, the right to vote and small business support were most frequently mentioned. For example, Patagonia tweeted, "The right to safely vote is fundamental to a healthy democracy and it is under attack", and in another tweet, Nisolo Shoes supported small businesses impacted by COVID-19, "Nisolo means not alone. Today we're joining forces with other small businesses and fellow@BCorporation to introduce you to brands we believe in and show our support so we can come out of this on the other side, together. \#IStandWithSmall".

Theme 4. Racial Issues. Among various causes, B Corps addressed racial issues most frequently. There were 18 tweets focusing on this issue. This was not surprising given the Black Lives Matter movement. Companies expressed their grief in response to the tragedy of George Floyd, Breonna Taylor, and others who lost their lives. Several tweets expressed their support for black leaders and black-owned businesses, in addition to encouraging people to speak up and take action to support racial equality and justice. For example, Bombas tweeted, "\#BlackLivesMatter. Bombas stands with our Black employees, partners and the Black community as a whole. We must all take action for justice against inequality and racism." Messages such as these align with the social responsibility embodied by B Corps.

Theme 5. Environmental Issues. In addition to racial issues, environmental issues were mentioned very commonly. Among the 16 tweets, initiatives and messages related to Earth Day or Month were most prevalent, but several companies raised awareness of additional issues, such as climate change, pollution, and environmental legislation. For example, ChicoBag highlighted the pollution in the oceans in the tweet, "Did you know we are dumping the equivalent of a garbage truck full of plastic into the ocean every minute? \#savetheplanet \#plasticpollution \#didyouknow \#plasticfreejuly". 
Theme 6. Sustainability Activism. Thirteen tweets corresponded to activism in sustainability. Several companies acknowledged the work of activists or tangible initiatives for policy shaping. Most of these tweets recognized activists who addressed racial or gender issues. For example, Another Tomorrow tweeted, "Today we launch WOMEN FOR TOMORROW, an ongoing series honoring incredible women who inspire us as people and in their work changing the landscape in their fields in service of a better tomorrow." Several tweets promoted companies' activism for environmental causes. For example, Patagonia tweeted, “@Interior's decision to open the Arctic Refuge for drilling ignores science $\mathcal{E}$ the downward spiral of the oil market, and fails to protect polar bear $\mathcal{E}$ caribou habitat. We stand with Gwich'in who rely on this sacred place to sustain their culture $\mathcal{E}$ way of life...".

Theme 7. Cause-related Donations/Fundraising. We found 13 tweets that communicated donations or fundraising for a certain cause. For this theme, we separated COVID-19 related donations or fundraising which will be covered in the next topic. While some of these were informational, telling their audiences about what and how they donated for a certain cause, more posts encouraged stakeholders to participate in donations or fundraising. For example, Oaklandish tweeted, "Thank you to everyone who has purchased this tee, let's keep it going! We just donated $\$ 4742$ to \#sooakland's campaign to rebuild Black-owned businesses in Oakland!..." In terms of method of donation, we found that these companies often used in-kind contributions, such as donating their products instead of cash or used a donation-with-purchase method. For example, Bixbee highlighted their buy-one-give-one model with this tweet: "What makes our backpacks unique you might ask?...For every backpack purchased, Bixbee proudly donates a schoolbag with supplies to kids in need around the world".

Theme 8. B Corp Promotion. B Corps were promoted in 11 tweets, wherein companies mentioned the purpose of B Corps in promoting sustainable business practices or mentioning @BCorp to increase the awareness of B Corps. Additionally, several companies actively promoted their B Corp certification status, which can serve as a sustainability cue to reinforce a sustainable brand identity. For example, ChicoBag tweeted, "We've been recognized as a Certified @BCorporation since 2013, which means we're now in our seventh year of doing business better. B Corp businesses have to meet the highest standards of verified social and environmental performance".

Theme 9. Media Engagement and Collaboration for a Cause. There were 10 tweets that engaged partners or influencers for a cause by collaborating or tagging them in their messages. For example, Another Tomorrow tweeted, "Thank you to@marinaa9214 and @marieclaire for including \#AnotherTomorrow in your roundup of sustainable fashion brands. \#conscioussourcing". To spread awareness and resources related to causes such as cancer awareness, supporting small businesses, and climate change, several companies engaged partners. For example, Wallaroo Hats shared the following tweet in partnership with the Melanoma Research Foundation: “...Facts from the Melanoma Research Foundation (MRF) @C ureMelanoma Melanoma FACT: Melanoma is not just a skin Cancer. It can develop anywhere on the body. Eyes, scalp, feet, mouth, etc. Stay Safe." In another example, Nisolo Shoes tweeted, "Today we're joining forces with other small businesses and fellow@BCorporation to introduce you to brands we believe in and show our support so we can come out of this on the other side, together. \#IStandWithSmall". Askov Finlayson leveraged Mary Heglar to raise awareness regarding climate change: “Climate change threatens the people and planet we love. @MaryHeglar's words remind us that we have to do whatever we can to protect our home-because home is always worth it". 


\subsubsection{Topic 2. COVID-19}

There were seven themes focusing on COVID-19. The most prevalent theme was COVID-19 related donations and fundraising, followed by messages regarding community support and connection. There were also frequent communications regarding public health messages to encourage consumer participation, realignment of production, various marketing mix messages (products, promotion, store operations, and distribution), and numerous collaborations to tackle COVID-19 related needs.

Theme 10. COVID-19 Related Donations/Fundraising. Fifty-two tweets corresponded to COVID-19 related donations and fundraising. This theme includes messages that highlight the companies' efforts intended to combat COVID-19 and assist those most impacted by the pandemic. In addition to sharing their own charitable initiatives, many companies encouraged their followers to participate as well. For example, Bombas tweeted, "... Bombas is teaming up with Village Den to collect critically needed items to donate to those who need them most. Let us know what giving back looks like in your community by tagging your post with \#givelocal and @bombas". Some of larger companies, such as Toms, used profit-based donations as shown in this tweet: "For every \$3 we make, we're donating $\$ 1$ to the TOMS COVID-19 Global Giving Fund-created to support long-time Giving Partners on the frontlines of COVID-19..." On the other hand, the majority of B Corps used either a form of in-kind donations with goods or donation-with-purchase promotions. Several companies, including Allbirds, Apolis, and Bombas, donated merchandise such as masks, shoes, and socks to frontline workers and used Twitter as a platform to inform and engage the public regarding these initiatives. Another major trend was the donation of goods to recognize and show appreciation for healthcare workers, which is also related to Theme 3. For example, Bombas shared, "We donated 15,000 pairs of socks to Founders Give, an organization that delivers much-needed items to those working in NYC's hospitals. We hope that these socks will give nurses a little comfort as they continue to keep our communities safe." In addition, many companies were involved in charitable initiatives that helped local communities and hard-hit industries, such as contributions to food banks and organizations assisting the hospitality sector. Lastly, several brands, such as Looptworks and United by Blue, demonstrated their sustainable brand identities by incorporating upcycled and salvaged materials in the goods that they were donating. For example, Looptworks tweeted, "From excess @United Airlines uniforms to 7500 face masks. We had the honor of upcycling masks out of United's excess retired uniforms...".

Theme 11. Community Engagement. In total, 35 tweets incorporated empathetic messages intended to support and connect with the community. Tweets corresponding to this theme focused on building a sense of community by providing emotional support, encouragement, and advice. For example, Olukai shared an uplifting message and music to help followers persevere through tough times: "Aloha means love, compassion and peace; we could all use a little more of that these days. That's why we've created a playlist to bring aloha vibes to you at the touch of a button-a 'play' button, that is. Listen now..." Other companies shared informative or encouraging messages with their followers that were also closely aligned with the brand's product offerings. For example, Athleta tweeted, "Need to connect to your body - and other humans? Grab your crew on video chat and break a sweat together. Screenshot and share the fun with @athleta and \#HomeBodies-Invite your friends and get moving!" In addition, companies shared a variety of resources to help their customers navigate these unprecedented times, including information on parenting, working remotely, and being mindful. 
Theme 12. Worker Appreciation. Another prevalent theme related to COVID-19 included 28 tweets that acknowledged healthcare workers, frontline staff, and employees. As discussed in Theme 1, the majority of tweets not only expressed gratitude but also donated merchandise, discounts, or other goods to these individuals as a token of appreciation. For example, Allbirds tweeted, "To our US healthcare community - we want to thank you for being on the front lines and helping to keep our communities healthy. We hope a pair of Tuke Matcha Wool Runners on us might be a small token of our appreciation..." In addition to expressing thankfulness to healthcare workers, other brands took the opportunity to recognize additional industries and groups most impacted by the pandemic, including essential workers like grocery store employees and those working in the hospitality industry. For example, Askov Finlayson shared, "COVID-19 has impacted all of us, but our friends in the hospitality industry have been hit especially hard, both here in Minnesota and across the country. We've seen firsthand the devastating effect this crisis is having on the lives of service professionals and wanted to help..." Likewise, Olukai tweeted, "Whether you're a health care worker, EMT, grocery clerk or delivery person, we would be honored to support you with a free pair of shoes. Visit ... to request your free pair, or pay it forward to someone deserving...".

Theme 13. Public Health/Safety Advocacy. Another common theme included 28 tweets that amplified public health/safety messages related to COVID-19 and encouraged civic participation. Many of these messages focused on encouraging followers to engage in prosocial behaviors to help curb the spread of COVID19 , such as staying home, social distancing, and wearing a mask. For example, Wallaroo Hats tweeted, "Happy Saturday Wallaroo Family! The Wallaroo Team is just checking in on you. Adventure Responsibly. Follow the recommendations and restrictions of local governments and health officials. Wash your hands, practice social distancing, and keep yourself healthy." In addition to messages encouraging responsible behavior for the greater collective good, other companies promoted consumer participation in COVID-19 related causes or user-generated content (UGC). For example, Therafit Shoe challenged followers to get involved by making homemade masks with this tweet, "Hospitals NEED your help solving the shortage of N95-type masks during the current COVID-19 pandemic. A homemade mask is a perfect alternative! Don't have a sewing machine, look on YouTube for a Glue Gun option!..".

Theme 14. Product/Promotion Realignment. In total, 27 tweets related to product/promotion realignment. Many companies shared information regarding COVID-19 related products or promotions. Companies manufactured additional products that were needed during the pandemic, such as masks. For example, ChicoBag tweeted, "Calling all planet saving pioneers! We've got a mask you can't resist: Reusable, Washable, Breathable, Ethically-made. Save the people. Save the planet. Shop yours now..." As shown in this tweet, B Corps emphasized the sustainable materials and production practices used in their COVID-friendly products. Some companies also highlighted how their merchandise was appropriate for the new normal of working from home. For instance, Tuckerman Co. shared this relatable message, "Working from home? Comfy, yet professional for those zoom calls..." Some companies featured alternative promotional messages due to COVID-19, such as this tweet from BTS Lingerie, "For Mother's Day this year we are encouraging gift cards, since we don't have control over shipping turnarounds and rely mainly on the post office and international post for free shipping these have all experienced delays and slowdowns due to increased volume during the pandemic." Finally, some companies, such as Cotopaxi, promoted the sale of COVID-19 related products along with a donation: "These days, not all heroes wear capes, but they do wear masks. Buy our new llama mask t-shirt, and a portion of sales will go to help hard-hit populations struggling to respond to the COVID-19 pandemic...". 
Theme 15. COVID-19 related Collaboration and Partner/Influencer Engagement. Seventeen tweets featured some form of collaboration and/or engaged external partners and influencers. Companies using this tactic tagged various organizations, individuals, and companies typically with the goal to fundraise for COVID-19 relief efforts or to discuss COVID-19 related initiatives. For example, Cotopaxi tweeted, “Take Note. Do Good. We've joined forces with the @utahjazz to help fight COVID-19 in our home state. All proceeds from this \#OneUtah $t$-shirt will be directed through @siliconslopes Serves to local partners on the battle's frontlines..." Similarly, Looptworks highlighted several sustainable partnerships with prominent companies, such as Starbucks and United Airlines, as shown in this tweet: “Through our partnership with @united, we diverted 12,284 pounds of uniforms from landfills to make 7500 face coverings to be worn by staff and passengers...".

Theme 16. Store Operation/Production/Distribution Realignment. Many companies shared updates regarding realignments to store operations, production, and distribution plans. In total, 16 tweets related to this theme, with a majority of these focusing on changes to store hours and operations and a shift from typical production practices to making masks and other essential items. For example, Patagonia tweeted, "Dear Patagonia community, As COVID-19 spreads-and is now officially a pandemic - we are taking additional safety measures to protect our employees and customers. The scale of impact is still unknown, and we want to do our part to protect our community..." Similarly, Eileen Fisher tweeted, "Starting today, we are temporarily closing our stores for two weeks. As conditions continue to evolve, we will monitor the advice given by expert agencies like the Centers for Disease Control and the World Health Organization to determine when it's safe to reopen." Given the need for masks, some companies announced recruiting additional workers to accommodate the shift in production. For instance, Looptworks tweeted, "No matter what you call yourself, we're looking for you! We are rapidly hiring for the Looptworks Seam Team to assist in mask making efforts..." Lastly, some companies addressed issues with shipping and delivery delays related to COVID-19.

\subsubsection{Topic 3. Product/Brand Promotion}

In total, 143 tweets corresponded to product/brand promotion. These promotions focus on highlighting their products, brand name, or value, rather than addressing sustainability or COVID-19 related issues. We found three underlying themes, including collaboration and engagement with partners/influencers/media, general product/brand promotion, and sales promotions.

Theme 17. Collaboration and Partner/Influencer/Media Engagement. The most common theme involved collaboration and/or engagement with a partner, influencer, or the media. Among these 56 tweets, 30 featured engagement with a partner or an influencer, while another 26 promoted the brand via a collaboration. $\mathrm{B}$ Corps engaged with a variety of individuals and groups, ranging from partners and influencers to major media outlets and other B Corps. For example, VPL NYC shared a tweet promoting that they were featured in Business Insider, while Eileen Fisher highlighted their participation in the Business of Fashion's summit on building a responsible fashion business. In addition to partnering with other B Corps, influencers, and organizations, many companies used collaborations to extend their reach and reinforce their brand values and sustainable identities. For instance, Athleta promoted their partnership with Olympic athlete Allyson Felix through this tweet "Legacies aren't created overnight. They're built by showing up - to train, strengthen, move in a bold direction. Introducing the first-ever limited edition Allyson Felix + Athleta collection-by female athletes, for female athletes. @allysonfelix". 
Theme 18. General Product/Brand Promotion. A total of 53 tweets promoted new products/collections or shared content related to their brand value or mission. Pictures of featured merchandise and links directing consumers to their websites were commonly used tactics, while a few brands also highlighted usergenerated images and reviews of merchandise. Many companies simply promoted their merchandise and product features like this tweet from Jelt Belt, "The new Jelt Venture. Made extra wide, extra strong and extra durable for extra adventures." In addition, some companies promoted their products along with product donations to people in need, as shown in this tweet from Bixbee: "What makes our backpacks unique you might ask? Swipe to see! For every backpack purchased, Bixbee proudly donates a schoolbag with supplies to kids in need around the world. \#OneHereOneThereMission".

Theme 19. Sales Promotions. There were 29 tweets corresponding to sales promotions. Many companies promoted sales by using special offers, discounts, contests, or giveaways. Numerous brands highlighted limited-time free shipping and special discounts. For example, Parker Clay tweeted, "Hang in there. We love you guys so much we've decided to celebrate the launch of our bone collection and our community coming together during this time by offering $25 \%$ off sitewide!..." Some price promotions highlighted the company's sustainability or tied messaging to COVID-19, such as this tweet from Known Supply, "Upgrade your Work From Home outfits with comfort $\mathcal{E}$ sustainability. Get FREE shipping on all styles when you use code 'STAYHOME'..." Others, such as Parker and Clay, highlighted price promotions with social impact as shown in this tweet: "Give \$50 Get \$50-This is the last week of this promotion for our VIPurpose ${ }^{\mathrm{TM}}$ Members. Click the link in our bio to spread the word about our impact in Ethiopia ... " In addition to price promotions, other tweets related to this theme promoted giveaways and contests, and many incorporated guidelines that required participants to follow the brand and retweet the message, thus enabling the brand to extend their reach on social media. For example, Merge 4 tweeted, "WEEKLY GIVEAWAY, This week's giveaway winners will win all 4 BRAND NEW @sandiegozoo socks!! These rad styles donate a portion of sales toward @sdzglobal conservation efforts, To Enter: FOLLOW @Merge4_ \& RETWEET!...".

Theme 20. Other. Lastly, there were five miscellaneous tweets that highlighted CEOs, production processes, and manufacturing. Specifically, AMS Fulfillment and Wallaroo Hats highlighted features published regarding their CEOs, and Tuckerman \& Co tweeted three posts highlighting their factories and production processes with the hashtag \#FactoryFriday.

\subsubsection{Topic 4. General Topics}

The last theme in the data pertained to general topics such as motivational content, personal stories of founders, recognizing employees, and other relatable content, such as major holidays. Of these 27 tweets, the most prevalent topic was the sharing of motivational content, which often included uplifting and engaging images and messages, such as pictures of sunsets and dogs or inspirational quotes. For example, to encourage more mindfulness and self-care, Tribe Alive tweeted, "A serene escape. Remember to take a moment for yourself today. Whatever it looks like-meditation, reading your favorite book, a breath of fresh air, calling someone you love. Take care of the wonderful, important person that is you..." Several companies highlighted major holidays, while others shared engaging content like this tweet from Cotopaxi: "If there's one made up holiday we can get behind, it's \#NationalPuppyDay. Today, we thank the good boys and girls out there for making us smile even when things get ruff..." Overall, many of these messages reflected the pandemic situation in some way. 


\subsection{Analysis of B Corps' Social Media Communications within the TBL Framework}

To examine how B Corps' social media communications are aligned with the TBL (Research Question 2), we classified the underlying themes of each topic according to the three pillars of the TBL (see Figure 2). Given that the TBL seeks to promote synergy among the three dimensions, we considered intersections among the dimensions and categorized the themes into three main dimensions and four intersections. When the messages regarding sustainable products or practices did not specify their impact, we distinguished them based on the cases that clearly communicated whether their sustainable practices addressed a social (e.g., fair trade, ethical sourcing) or environmental (e.g., upcycled materials, carbon neutral) dimension. Furthermore, we separated messages related to COVID-19 as a special case to illustrate how B Corps coped with a crisis and communicated different areas of sustainability amid the pandemic.

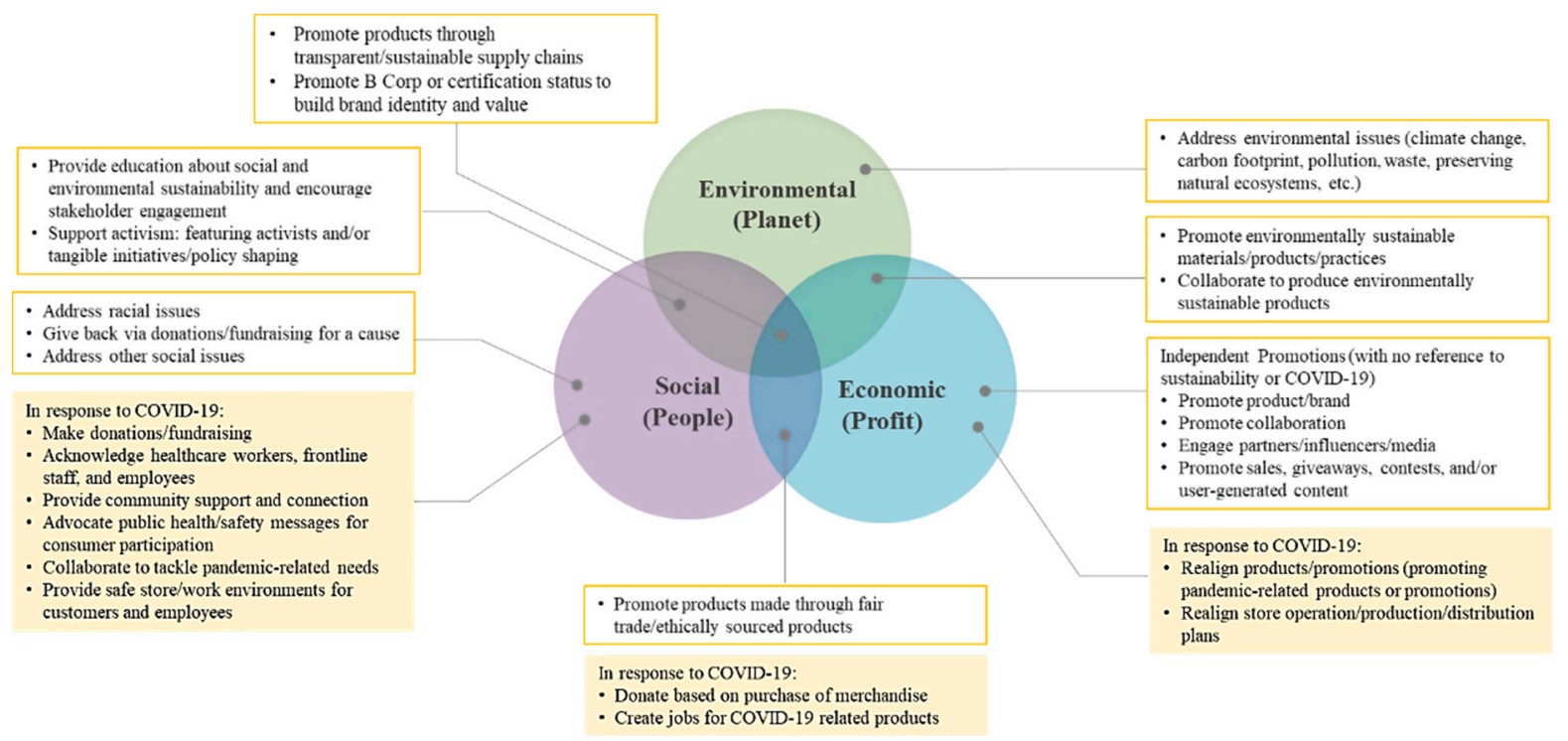

Figure 2. AFA B Corps' Social Media Communications during COVID-19: Through the Lens of the TBL.

As shown in Figure 2, B Corps used a range of approaches to address the three pillars of the TBL. For example, raising awareness, taking a position, and encouraging affirmative actions regarding racial inequality were salient social issues communicated by B Corps. Several corporations addressed climate change, pollution, waste, etc. to increase environmental awareness and encourage positive action from stakeholders to preserve the planet. Corporations also promoted their products and brand values to grow profitability by using various sales promotion tactics or engaging the media, partners, influential accounts or customers through user-generated content. More interestingly, we found examples of strategies that addressed multiple dimensions of the TBL, for example, promoting products made through sustainable/transparent practices to address profitability as well as the environmental and social aspects of the TBL. Promoting the B Corp model and certification was another example that addressed the synergy among the three aspects of the TBL. Therefore, B Corps in the AFA sectors are collectively attempting to support and communicate the three pillars of the TBL and leverage strategies to promote balance between each dimension. However, when we closely examined each individual company, we found that not all B Corps addressed all three pillars of the TBL. For example, as depicted in Table 2, Bixbee, Parker Clay, Merge4, and Wallaroo Hat Company primarily utilized Twitter for product/brand promotion. 
Table 2. Impact and Social Media Performance ${ }^{\mathrm{a}}$.

\begin{tabular}{|c|c|c|c|c|c|c|}
\hline Company Name & $\begin{array}{l}\text { Overall } \\
\text { B-Score }\end{array}$ & $\begin{array}{c}\text { Highest } \\
\text { Impact Area }^{c}\end{array}$ & $\begin{array}{c}\text { Dominant Topics of Most } \\
\text { Engaging Posts }\end{array}$ & \# of Followers & Posts/Week ${ }^{\mathrm{d}}$ & AER/Post ${ }^{e}$ \\
\hline TOMS & 121.5 & $\mathrm{C}$ & $\begin{array}{l}\text { COVID-19; Product/Brand } \\
\text { Promotion }\end{array}$ & $1,874,384$ & 5.96 & $0.001 \%$ \\
\hline Patagonia & 151.4 & $\mathrm{C}$ & Social \& Environmental & 498,890 & 5.63 & $0.274 \%$ \\
\hline Oaklandish & 83.7 & $\mathrm{C}$ & Product/Brand Promotion & 69,105 & 6.08 & $0.064 \%$ \\
\hline Athleta & 84.3 & $\mathrm{C}$ & Product/Brand Promotion & 48,486 & 4.42 & $0.025 \%$ \\
\hline Allbirds & 89.4 & $\mathrm{E}$ & COVID-19; Social \& Environmental & 25,922 & 1.50 & $0.631 \%$ \\
\hline VPL & 103.5 & $\mathrm{E}$ & COVID-19 & 25,226 & 0.21 & $0.008 \%$ \\
\hline Nisolo & 115.4 & $\mathrm{C}$ & Social \& Environmental; COVID-19 & 17,243 & 1.25 & $0.015 \%$ \\
\hline Bombas & 89.2 & C & $\begin{array}{c}\text { COVID-19; Product/Brand } \\
\text { Promotion }\end{array}$ & 16,406 & 2.33 & $0.111 \%$ \\
\hline Karen Kane & 85.3 & $\mathrm{C}$ & General Topics & 16,270 & 11.96 & $0.013 \%$ \\
\hline Cotopaxi & 93.6 & $\mathrm{C}$ & COVID-19 & 14,518 & 0.67 & $0.099 \%$ \\
\hline United by Blue & 84.1 & $\mathrm{C}$ & Social \& Environmental & 12,104 & 6.21 & $0.030 \%$ \\
\hline Eileen Fisher & 96.2 & $\mathrm{E}$ & Social \& Environmental & 11,603 & 3.38 & $0.091 \%$ \\
\hline Therafit Shoe & 80.5 & $\mathrm{C}$ & Product/Brand Promotion & 8220 & 6.04 & $0.003 \%$ \\
\hline Apolis & 82.7 & $\mathrm{C}$ & $\begin{array}{c}\text { Product/Brand Promotion; Social \& } \\
\text { Environmental }\end{array}$ & 6425 & 0.42 & $0.006 \%$ \\
\hline ChicoBag & 114.5 & $\mathrm{E}$ & Social \& Environmental & 6070 & 0.96 & $0.027 \%$ \\
\hline Olukai & 81.2 & W & COVID-19 & 5576 & 0.33 & $0.159 \%$ \\
\hline Between the Sheets & $\mathrm{N} / \mathrm{A}$ & & Social \& Environmental & 5377 & 0.29 & $0.027 \%$ \\
\hline Helpsy & 85.6 & $\mathrm{E}$ & Social \& Environmental & 5358 & 0.17 & $0.107 \%$ \\
\hline Creative Action Network & 113.1 & $\mathrm{C}$ & Social \& Environmental & 4807 & 8.17 & $0.045 \%$ \\
\hline Ecobags & 91.3 & $\mathrm{E}$ & Social \& Environmental & 4029 & 0.25 & $0.041 \%$ \\
\hline Askov Finlayson & 80.7 & $\mathrm{E}$ & Social \& Environmental & 3734 & 0.67 & $0.260 \%$ \\
\hline Looptworks & 111.5 & $\mathrm{C}$ & Social \& Environmental & 2376 & 3.25 & $0.231 \%$ \\
\hline Bixbee & 81.5 & $\mathrm{C}$ & Product/Brand Promotion & 1715 & 1.83 & $0.017 \%$ \\
\hline Dhana Inc. & 151.9 & $\mathrm{C}$ & Social \& Environmental & 1699 & 0.75 & $0.006 \%$ \\
\hline AMS Fulfillment & 85.2 & W & COVID-19; Social \& Environmental & 1440 & 1.21 & $0.007 \%$ \\
\hline Wallaroo Hat Company & 81.1 & $\mathrm{C}$ & Product/Brand Promotion & 828 & 1.79 & $0.079 \%$ \\
\hline Tribe Alive & $\mathrm{N} / \mathrm{A}$ & & $\begin{array}{c}\text { Product/Brand Promotion; Social \& } \\
\text { Environmental }\end{array}$ & 734 & 8.33 & $0.027 \%$ \\
\hline Known Supply & 86.9 & $\mathrm{C}$ & COVID-19; Social \& Environmental & 453 & 1.08 & $0.662 \%$ \\
\hline Parker Clay & $\mathrm{N} / \mathrm{A}$ & & Product/Brand Promotion & 442 & 8.17 & $0.050 \%$ \\
\hline Jelt Belt & 83.3 & $\mathrm{C}$ & Product/Brand Promotion & 428 & 0.75 & $0.014 \%$ \\
\hline Merge4 & 98 & $\mathrm{C}$ & Product/Brand Promotion & 357 & 3.00 & $1.894 \%$ \\
\hline Tuckerman \& Co. & $\mathrm{N} / \mathrm{A}$ & & $\begin{array}{c}\text { Product/Brand Promotion; Social \& } \\
\text { Environmental }\end{array}$ & 330 & 1.79 & $0.155 \%$ \\
\hline Gallant International & 86.7 & $\mathrm{C}$ & Social \& Environmental & 145 & 0.63 & $0.503 \%$ \\
\hline Another Tomorrow & 80.3 & $\mathrm{E}$ & Social \& Environmental & 43 & 0.21 & $6.047 \%$ \\
\hline
\end{tabular}

a The company list is sorted by the number of followers. ${ }^{b}$ Overall B Impact Score is verified by B Lab. The mean is calculated based on the available scores $(M=95.79 ; S D=19.41)$, and B Corps above the mean are bolded. ${ }^{\mathrm{c}}$ Highest Impact Area is identified based on the scores for the five impact areas ( $\mathrm{C}$ for Community; $\mathrm{E}$ for Environment; $\mathrm{W}$ for Workers). ${ }^{\mathrm{d}}$ Posts include original tweets made by the company from 11 March 2020 to 11 September 2020. ${ }^{\text {e }}$ Average Engagement Rate per Post is calculated as the total number of engagements per post divided by the number of followers (expressed as a percentage). The number of posts per week of the industry benchmark in 2020 was reported as 2.4 on Twitter. The average engagement rate of the industry benchmark during the study time period was reported as $0.058 \%$. B Corps above the industry benchmark are bolded.

Additionally, the COVID-19 pandemic immensely influenced how B Corps addressed the TBL. In the social dimension, B Corps focused more on community support to build resilience through giving, empathy, and community engagement. They also showed appreciation to healthcare workers, frontline staff, and employees and adapted operational policies for better, safer store/working environments for their employees and customers. In the economic dimension, business activities from production to promotions to distribution were realigned to cope with the pandemic situation. Some of them developed collaborations or engaged influential profiles to increase stakeholder engagement and the visibility of the brand. Additionally, B Corps leveraged strategies that intersected with the economic and social aspects of the TBL, for example, giving consumers the opportunity to purchase products to fund donations of products to those in need, as well as creating jobs to serve increasing demand related to COVID-19. 


\subsection{Analysis of B Corps' Social Media Communications within the TBL Framework}

To answer Research Question 3, we examined Twitter performance among the B Corps and in comparison with the industry benchmarks. To compare, we highlighted (in bold) companies above the industry benchmarks in Table 2. The highest number of followers was $1,874,384$ and the lowest was $43(M d n=5368)$. While 12 brands $(35.29 \%)$ had greater than 10,000 followers, nine brands (26.47\%) had fewer than 1000 followers. The average number of weekly posts that B Corps created during the six months and the number of followers varied significantly across the brands. The average weekly posts ranged from 0.17 posts to 11.96 posts $(M=2.93, S D=3.06)$. Karen Kane created the highest post volume (11.96 posts/week), followed by Tribe Alive ( 8.33 posts/week). As of January 2020, the fashion industry's benchmark for the weekly post number on Twitter was 2.4 posts [31]. On average, B Corps in the AFA sectors posted slightly above the industry benchmark. However, 13 brands (38.24\%) posted none to one post per week, overlooking the importance of consistent communication with their audience during a difficult time.

The average engagement rate per post (AER/Post) is calculated as the total engagements per post divided by the number of followers (expressed as a percentage) where engagements are measured by the number of likes and retweets each post received. B Corps' AER/Post was $0.35 \%(S D=1.07)$. The fashion industry's benchmark for Twitter AER/Post during the same study timeframe was $0.06 \%$ [32]. Collectively, B Corps in our sample far exceeded the industry benchmark in terms of AER/Post. However, given that most B Corps are small businesses and many of these brands' follower size is much smaller than larger businesses, AER/Post can be higher. Engaging the audience becomes harder as the follower size increases, and a popular account is likely to attract automated bot social accounts [33]. For example, TOMS had the highest follower size, but their AER/Post was $0.001 \%$. In contrast, Another Tomorrow had the lowest follower size of 43 but had the highest AER/Post, $6.047 \%$, meaning that although this brand had very few followers, their followers were actively engaged with the brand's posts. In addition to the follower numbers, AER/Post decreases when the number of posts gets higher. For example, while Another Tomorrow's AER/Post was $6.047 \%$ with 0.21 tweets per week, Karen Kane's AER/Post was $0.013 \%$ with 11.96 posts per week. These examples indicate that simply increasing the number of followers or weekly posts does not result in a higher engagement rate. These results also highlight the importance of creating quality content that truly resonates with their target audience to enhance the average engagement rate.

To further examine Research Question 3, we qualitatively examined if brands with large followers exhibit any patterns in the topical focus of the most engaging tweets (i.e., focusing on social/environmental issues, COVID-19, or product/brand promotion), weekly post volume, or AER/Post. First, we found no association between the number of followers and topical focus. For example, TOMS and Patagonia were the brands with the largest followers, but while TOMS mostly engaged with content related to COVID-19 and product/brand promotion, Patagonia mostly engaged with social and environmental issues. However, when we compared the brands by B impact scores, brands with high impact scores (except TOMS) tended to engage more with environmental and social issues, as opposed to content related to product/brand promotion or COVID-19 (see Table 2). For example, Dhana Inc. and Patagonia earned the highest area scores on the community impact, and their Twitter communications also highlighted a number of social and environmental causes, including Black Lives Matter, workers' rights, and environmental activism. Second, although there was no strong association between the number of followers and the number of weekly posts, many brands with relatively larger followers (e.g., TOMS, Patagonia, Oaklandish, Athleta, Karen Kane, etc.) tended to post more frequently than the industry benchmark. Third, as discussed above, a higher number of followers was not translated into a higher AER/Post. For example, TOMS with the largest following had one of the lowest AER/Post. On the other hand, Bombas and Eileen Fisher had a fraction of TOMS's follower number but had much higher AER/Post that exceeded the industry benchmark. 


\section{Discussion and Conclusions}

Using a qualitative research approach, we examined how B Corps in the AFA sectors in the U.S. leverage social media to communicate and engage with their stakeholders, especially during the COVID-19 crisis. We focused on B Corps' communications during this challenging time because the pandemic has been marked with an increased emphasis on sustainability among consumers [5].

Consistent with B Corps' commitment to sustainability and creating positive change in the community/society, we found that social and environmental issues and COVID-19 were the two dominant topics communicated on social media, followed by product/brand promotion and general messages. We further identified a range of underlying themes that emerged from each topic. The topic corresponding to social and environmental messages had nine themes, including communicating about sustainable products or practices, raising awareness regarding sustainable issues through education and stakeholder engagement, addressing social issues such as racism, discussing environmental issues, supporting activism, and promoting B Corp and certification. The COVID-19 related topic included a variety of business decisions or activities to cope with the crisis, ranging from realignment strategies in production, operations, promotions, and distribution to supporting community resilience through donations / fundraising, community support, and engagement. On the other hand, messages corresponding to the product/brand promotion topic focused on general promotional messages without direct reference to sustainability or COVID-19. Specifically, B Corps promoted their offerings through collaborations, engaging partners/influencers/media, and engaging consumers through sales/discounts, giveaways, contests, and user-generated content. Finally, B Corps occasionally shared general messages by means of relatable events, stories, or photos. Based on the thematic analysis, we draw theoretical and practical implications of this study by applying the TBL and examining Twitter performance.

\subsection{Theoretical Implications}

The findings of our study provide several theoretical implications. First, to the best of our knowledge, this study is the first to examine B Corps' social media communications through the lens of the TBL framework. The importance of sustainability communications on social media is rapidly growing due to the need for transparent and legitimate communications with internal and external stakeholders [6,7]. Our qualitative approach contributes to the sustainability communication literature by highlighting the importance of aligning social media communications with the TBL to achieve long-term sustainability.

Second, the TBL social media communication framework developed in this study is grounded in multiple real-world cases of B Corps which represent the AFA sector in the U.S. Our qualitative data and theoretical analysis fill a gap in the literature because there have been limited documentations on B Corps' sustainability models and communications [34]. We found that, collectively, social media communications of B Corps address interactions among the three dimensions of the TBL, but individually, each corporation has potential to further develop synergy among the three pillars of sustainability. To this end, the framework developed in this study can serve as a guide or starting point for corporations to address and conserve various types of natural, social, and economic capital. This framework can be used to help B Corps or other sustainability-driven businesses, individually or collectively, to evaluate whether their communications on social media aligned with the TBL and identify the strengths and the areas to improve for effective communications.

Lastly, findings from this study attest that exogenous shocks, such as COVID-19, do not divert attention from the significance of the TBL. Instead, such shocks can reinforce and offer new and creative opportunities to address the TBL. This is critical given the position of B Corps as the trailblazers of positive change. Their communication to stakeholders can be instrumental in developing benchmarks and stakeholder expectations that businesses should not focus on profits alone even during a crisis. Our findings highlight that corpora- 
tions have obligations to address all three pillars of the TBL creatively and in ways that create value, even when tensions exist between the dimensions [20,34].

\subsection{Practical Implications}

Sustainability communications on social media allow stakeholders to better understand B Corps' purpose and initiatives and directly engage with them. Corporate transparency and engagements in communications can further support consumer decisionmaking and drive sustainable actions [35]. Although B Corps in the AFA sectors collectively or on average met or exceeded industry benchmarks, we found that many of them did not fully leverage Twitter, and their individual performance showed somewhat weak presence in terms of the follower size, weekly post numbers, and/or AER/Post. Lee et al. [36] found that corporations with higher CSR ratings tend to have a larger following on Twitter and grow their account faster than corporations with lower ratings. Similarly, it was expected that B Corps with higher B impact scores have larger followers and communicate more frequently with their audiences. However, in our data, there was no clear sign that $B$ impact scores are positively associated with the number of followers or the frequency of posts. Although the number of followers is one of the vanity metrics and cannot be used as a metric to determine the success of an account or a campaign, companies should make continuous efforts to grow their followers and reach their target audience. We suggest that especially high performing B Corps focus on building their community by improving the frequency of communication and actively engaging them with content that resonates with the interests of various stakeholders.

In addition, while we did not formally code for one-way vs. two-way communication, in our analysis, we found that the majority of the tweets focused on broadcasting/one-way communication rather than two-way communication. Previous studies have shown that messages that engage stakeholders in dialogue can be more effective than pushing information in one way $[10,12]$. Moreover, companies increasingly engage partners, influencers, or third-party actors to increase engagement and reach a wider audience [37]. In our data, we noticed that some brands often engage mass media or journalists to acknowledge their mentions in the press as well as bring the public's attention to their commitment to sustainability and to promote their brands/products, as well as COVID-19 related messages. Companies could also utilize interactive methods to make content more engaging and entertaining, such as motivating consumers to share their content, hosting contests or promotions, polling consumers, and creating sustainability-related conversations, which could improve engagement [11,12].

Furthermore, social media can be strategically used to support or improve an organization's TBL [38]. Even though social media offers a viable channel to disseminate organizational values and initiatives, the message content communicated on social media can vary in its effectiveness for engaging and building trust with stakeholders. In terms of message content, some companies heavily focused on educational content or information sharing about their sustainability performance. While this is certainly necessary to increase awareness and make a positive impact, companies may consider balancing the content to meet the interests of various internal and external stakeholders by providing a combination of promotional (economic), social, and environmental topics. This can be helpful in increasing stakeholder awareness regarding responsible business practices and driving positive change.

Lastly, previous studies also warn that external communication of sustainability could invite more skepticism by consumers, the media, and other external stakeholders [6], thus leading some companies to engage in greenhushing. However, companies can reduce such risks and gain positive public perceptions by including third-party endorsements or certifications or engaging independent organizations, activists, or influencers in their communications of sustainability $[22,23,37,39]$. In this regard, given that B Corp certification is granted to businesses that meet the highest standards of sustainable practices [3,34,39], certified B Corps have a competitive advantage to build a stronger community rooted 
in transparency. However, because many consumers are still not familiar with B Corp certification [39], B Corps should create more clear and engaging communications on social media to enhance the value of B Corp certification and strengthen organizational identity.

\section{Limitations and Future Research}

This study has several limitations which can provide foundations for future research. First, we focused on B Corps' communications on Twitter, limiting the generalizability of the findings. Each platform has unique characteristics and focuses on different functionalities. For example, according to Kiezmann et al. [40], while Twitter is known for conversations, Facebook is characterized by relationship building and Instagram by identity building. Increasingly, more businesses utilize various social media platforms to reach wider audiences, tailoring social media content to enhance customer engagement and experience. Therefore, it would be beneficial to explore how B Corps communicate their messages and promote their brand identities across different social media platforms.

Second, this study focused on the apparel, footwear, and accessories sectors. Considering that each industry poses unique problems and issues corresponding to sustainability [25], there is a need to examine diverse industries and compare communication strategies across different industry sectors, thus providing more comprehensive and integrated implications. Moreover, identifying similarities and differences among different industry sectors can promote industry collaborations or synergy to discover creative solutions for sustainability.

Third, in this study we focused on message content, but future research may investigate the interaction of message content and different media formats (e.g., images, videos, links, text, and combinations) or tactics (e.g., the types or number of hashtags, tagging) as these message attributes can impact consumer engagement. Lastly, this study employed a qualitative method to examine an under-researched phenomenon of B Corps' social media communications during a crisis. Future research should integrate a quantitative approach to extend our findings and investigate consumer evaluations of various message strategies in sustainability communications on social media. With the further extension of the study to different industry sectors, platforms, message strategies, and methodologies, we believe that future research can contribute to building a comprehensive theoretical framework that promotes balance among the three pillars of the TBL and improves transparency in social media communications among sustainability-driven businesses.

Author Contributions: Conceptualization, S.-E.B. and M.M.; Methodology, M.M. and S.-E.B.; Software, M.M. and S.-E.B.; Formal Analysis and Investigation, M.M., S.-E.B. and W.G.; Resources, S.-E.B.; Data Curation, S.-E.B.; Writing-Original Draft Preparation, M.M.; Writing-Review and Editing, S.-E.B. and W.G.; Visualization, M.M., S.-E.B. and W.G.; Supervision, S.-E.B. All authors have read and agreed to the published version of the manuscript.

Funding: This research received no external funding.

Institutional Review Board Statement: Not applicable.

Informed Consent Statement: Not applicable.

Data Availability Statement: The data presented in this study are available on request from the corresponding author.

Conflicts of Interest: The authors declare no conflict of interest.

\section{References}

1. Kim, S.; Karlesky, M.; Meyers, C.; Schifeling, T. Why Companies Are Becoming B Corporations. Harv. Bus. Rev. 2016, 17, 1-5. Available online: https:/ /hbr.org/2016/06/why-companies-are-becoming-b-corporations (accessed on 1 March 2021).

2. Elkington, J. 25 Years Ago I Coined the Phrase "Triple Bottom Line". Here's Why It's Time to Rethink It. Harv. Bus. Rev. 2018, 25, 2-5. Available online: https:/ / hbr.org/2018/06/25-years-ago-i-coined-the-phrase-triple-bottom-line-heres-why-im-givingup-on-it (accessed on 1 March 2021).

3. Certified B Corporation. 2021. Available online: https://bcorporation.net/certification (accessed on 1 June 2020). 
4. Gehman, J.; Grimes, M. Hidden badge of honor: How contextual distinctiveness affects category promotion among certified b corporations. Acad. Manag. Sci. 2017, 60, 2294-2320. [CrossRef]

5. IBM Institute of Business Value. Sustainability at a Turning Point: Consumers Are Pushing Companies to Pivot. 2021. Available online: https://www.ibm.com/thought-leadership/institute-business-value/report/sustainability-consumer-research?utm_ medium=Email\&utm_source=Newsletter\&utm_content=000038GP\&utm_term=10012001\&utm_campaign=PLACEHOLDER\& utm_id=launch\# (accessed on 12 May 2021).

6. Araujo, T.; Kollat, J. Communicating effectively about CSR on Twitter: The power of engaging strategies and storytelling elements. Internet Res. 2018, 28, 419-431. [CrossRef]

7. Bani-Khalid, T. Examining the quantity and quality of online sustainability disclosure within the Jordanian industrial sector: A test of GRI guidelines. Probl. Perspect. Manag. 2019, 17, 141-152. [CrossRef]

8. Tanford, S.; Kim, M.; Kim, E.J. Priming social media and framing cause-related marketing to promote sustainable hotel choice. J. Sustain. Tour. 2020, 28, 1762-1781. [CrossRef]

9. U.S. Chamber of Commerce Foundation Corporate Citizenship Center \& IBM. The CSR Effect: Social Media Sentiment and the Impact on Brands. 2017. Available online: https:/ / www.uschamberfoundation.org/reports/csr-effect-social-media-sentimentand-impact-brands?cm_mc_uid=974331508313150 (accessed on 12 May 2021).

10. Kang, M.Y.; Park, B. Sustainable corporate social media marketing based on message structural features: Firm size plays a significant role as a moderator. Sustainability 2018, 10, 1167. [CrossRef]

11. Artemova, A. Sustainability Communication on Social Media: A Study on the Most Sustainable Brands in Finland. Master's Thesis, Jyväskylä University, Jyväskylä, Finland, 2020. Available online: https://jyx.jyu.fi/bitstream/handle/123456789/69769/ 1/URN\%3ANBN\%3Afi\%3Ajyu-202006084026.pdf (accessed on 1 March 2021).

12. Okazaki, S.; Plangger, K.; West, D.; Menéndez, H.D. Exploring digital corporate social responsibility communications on Twitter. J. Bus. Res. 2020, 117, 675-682. [CrossRef]

13. McFall-Johnsen, M. These Facts Show How Unsustainable the Fashion Industry Is. World Economic Forum. 2020. Available online: https: / /www.weforum.org/agenda/2020/01/fashion-industry-carbon-unsustainable-environment-pollution/ (accessed on 25 June 2021).

14. Brundtland, G. Report of the World Commission on Environment and Development: Our Common Future. United Nations General Assembly Document A/42/427. 1987. Available online: https://sustainabledevelopment.un.org/content/documents/ 5987our-common-future.pdf (accessed on 12 May 2021).

15. Elkington, J. Cannibals with Forks: The Triple Bottom Line of Twenty-First Century Business; Capstone/Oxford; Oxford University Press: Oxford, UK, 1997.

16. Shnayder, L.; van Rijnsoever, F.J.; Hekkert, M.P. Putting your money where your mouth is: Why sustainability reporting based on the triple bottom line can be misleading. PLOS ONE 2015, 10, e0119036. [CrossRef] [PubMed]

17. Green, K.W., Jr.; Zelbst, P.J.; Meacham, J.; Bhadauria, V.S. Green supply chain management practices: Impact on performance. Supply Chain Manag. Int. J. 2012, 17, 290-305. [CrossRef]

18. Schaltegger, S.; Burritt, R. Measuring and managing sustainability performance of supply chains: Review and sustainability supply chain management framework. Supply Chain Manag. Int. J. 2014, 19, 232-241. [CrossRef]

19. Epstein, M.J.; Elkington, J.; Leonard, H.B.D. Making Sustainability Work: Best Practices in Managing and Measuring Corporate Social, Environmental and Economic Impacts; Routledge: London, UK, 2008. [CrossRef]

20. Walker, K.; Yu, X.; Zhang, Z. All for one or all for three: Empirical evidence of paradox theory in the triple-bottom-line. J. Clean. Prod. 2020, 275, 122881. [CrossRef]

21. Isil, O.; Hernke, M. The triple bottom line: A critical review from a transdisciplinary perspective. Bus. Strategy Environ. 2017, 26, 1235-1251. [CrossRef]

22. Cho, M.; Furey, L.D.; Mohr, T. Communicating corporate social responsibility on social media: Strategies, stakeholders, and public engagement on corporate Facebook. Bus. Commun. Q. 2017, 80, 52-69. [CrossRef]

23. Kapoor, P.S.; Balaji, M.S.; Jiang, Y. Effectiveness of sustainability communication on social media: Role of message appeal and message source. Int. J. Contemp. Hosp. Manag. 2021, 33, 949-972. [CrossRef]

24. Johansen, S.T.; Ellerup Nielsen, A. Strategic stakeholder dialogues: A discursive perspective on relationship building. Corp. Commun. Int. J. 2011, 16, 204-217. [CrossRef]

25. Reilly, A.H.; Hynan, K.A. Corporate communication, sustainability, and social media: It's not easy (really) being green. Bus. Horiz. 2014, 57, 747-758. [CrossRef]

26. Pilar, L.; Stanislavska, L.K.; Pitrova, J.; Krejci, I.; Ticha, I.; Chalupova, M. Twitter analysis of global communication in the field of sustainability. Sustainability 2019, 11, 6958. [CrossRef]

27. Etter, M. Broadcasting, reacting, engaging: Three strategies for CSR communication in Twitter. J. Commun. Manag. 2014, 18, 322-342. [CrossRef]

28. Tölkes, C. The role of sustainability communication in the attitude-behaviour gap of sustainable tourism. Tour. Hosp. Res. 2020, 20, 117-128. [CrossRef]

29. Ginder, W.; Byun, S.-E.; Kwon, W.-S. Effects of internal-external congruence-based CSR positioning: An attribution theory approach. J. Bus. Ethics 2019, 169, 355-369. [CrossRef] 
30. Ginder, W. An Attribution Theory Approach to Corporate Social Responsibility (CSR) Communication: Consumer Response to Consistency-Based CSR Positioning. Doctoral Dissertation, Auburn University, Auburn, AL, USA, 2016. Available online: https: / / etd.auburn.edu/bitstream/handle/10415/5417/Whitney\%20Ginder_Dissertation.pdf?sequence=2 (accessed on 25 June 2021).

31. Feehan, B. 2021 Social Media Industry Benchmark Report. Available online: https://www.rivaliq.com/blog/social-mediaindustry-benchmark-report/ (accessed on 16 February 2021).

32. Jipa, A. 2021 Social Media Industry Benchmarks-Know Exactly Where You Stand in Your Market. Available online: https: / / www.socialinsider.io/blog/social-media-industry-benchmarks/ (accessed on 19 January 2021).

33. Leone, C. Which Social Media Sites Get the Most Engagement? Available online: https://www.webstrategiesinc.com/blog/ which-social-media-sites-get-the-most-engagement (accessed on 16 July 2018).

34. Tabares, S. Certified B corporations: An approach to tensions of sustainable-driven hybrid business models in an emerging economy. J. Clean. Prod. 2021, 317, 128380. [CrossRef]

35. Turunen, L.L.M.; Halme, M. Communicating actionable sustainability information to consumers: The Shades of Green instrument for fashion. J. Clean. Prod. 2021, 297, 126605. [CrossRef]

36. Lee, K.; Oh, W.; Kim, N. Social media for socially responsible firms: Analysis of fortune 500's Twitter profiles and their CSR/CSIR ratings. J. Bus. Ethics 2013, 118, 791-806. [CrossRef]

37. Berne-Manero, C.; Marzo-Navarro, M. Exploring how influencer and relationship marketing serve corporate sustainability. Sustainability 2020, 12, 4392. [CrossRef]

38. Milde, K.; Yawson, R.M. Strategies for social media use in nonprofits. J. Manag. Policy Pract. 2017, 18, $19-27$.

39. Moroz, P.W.; Gamble, E.N. Business model innovation as a window into adaptive tensions: Five paths on the B Corp journey. J. Bus. Res. 2021, 125, 672-683. [CrossRef]

40. Kietzmann, J.; Hermkens, K.; McCarthy, I.; Silvestre, B. Social media? Get serious! Understanding the functional building blocks of social media. Bus. Horiz. 2011, 54, 241-251. [CrossRef] 